\title{
影响东北初夏和盛夏降水年际变化的环流 特征分析
}

沈柏竹 (1) (2), 林中达 ${ }^{(3 *}$, 陆日宇 ${ }^{(3)}$, 廉毅 (1) (2)

(1) 吉林省气象科学研究所, 长春 130062 ;

(2) 中高纬度环流系统与东亚季风研究开放实验室, 长春 130062;

(3) 中国科学院大气物理研究所, 北京 100029

* 联系人, E-mail: zdlin@mail.iap.ac.cn

收稿日期: 2010-04-14; 接受日期: 2010-08-03

国家科技支撑计划(编号: 2009BAC51B04，2007BAC29B01)、中国科学院创新项目(编号：KZCX2-YW-220)、国家自然科学基金(批准号： 40575047, 40705036)和中国气象局新技术推广项目(编号: CMATG2009MS01)资助

摘要东北地区是我国主要的粮食生产基地, 而夏季是东北农作物的主要生长季, 也是降水集中的季节, 降水量的多少及其分布是影响东北地区粮食产量的重要因素之 一. 本文利用中国东北地区 79 个台站观测的月平均降水资料和 ECMWF 再分析资料, 通过相关分析和回归分析, 讨论了影响东北地区夏季 5 8 月降水年际变化的大尺度环 流特征. 结果发现: 东北地区降水年际变化对应的环流异常在 5,6月(初夏)和 7,8 月(盛 夏)具有明显不同的特征; 初夏降水异常以冷涡活动的影响为主, 而盛夏则以东亚夏季 风的影响为主. 初夏, 东北地区降水偏多年, 东北地区西北部出现随高度向西倾斜的异 常气旋性环流, 东北地区冷涡活动频繁. 盛夏, 东北地区降水异常主要受到局地对流层 高层东亚高空西风急流北移以及低层的西太平洋副热带高压西伸北进的影响. 随着西 太平洋副热带高压西北侧西南风异常的加强, 向北输送到东北地区的水汽显著增多, 东北地区盛夏降水偏多. 此外, 与 7 月份相比, 8 月东北降水除了受到夏季风的影响以 外，还受到中高纬度东北亚阻塞高压的影响.
关键词

东北夏季降水

年际变化

冷涡

西太平洋副热带高压

东亚高空西风急流
东北地区是我国最大的商品粮基地和农业生产 最有发展潜力的地区之一. 夏季是东北农作物的主 要生长季, 也是降水集中的季节, 降水量的多少及其 分布是影响东北地区粮食产量的重要因素之一. 因 此, 研究东北地区降水的年际变化对于我国的粮食 生产安全具有非常重要的意义.

东亚夏季风降水带的季节推进具有显著的阶段
性：在我国, 5 6 月降水带位于长江以南地区, 6 月下 旬降水带北进到江淮流域, 而 8 月降水带出现在我国 华北和东北地区 ${ }^{[1 \sim 3]}$. 廉毅等 ${ }^{[4]}$ 进一步分析了东亚夏 季风在中国东北地区的推进过程, 指出东亚夏季风 7 月下旬在东北地区建立, 而在 8 月中旬开始从东北地 区向南撤退.

东北地区夏季降水除了存在显著的季节演变特

英文引用格式: Shen B Z, Lin Z D, Lu R Y, et al. Circulation anomalies associated with interannual variation of early- and late-summer precipitation in Northeast China. Sci China Earth Sci, 2011, doi: 10.1007/s11430-011-4173-6 
征以外, 还存在明显的年际变化. 孙力等 ${ }^{[5]}$ 利用 $\mathrm{EOF}$ 方法分析了夏季平均东北降水年际变化的主要特征, 指出东北夏季降水的第一主分量对应着东北夏季降 水的区域一致性变化; 区域平均降水对应的水汽主 要来源于热带南海、南亚季风区以及副热带西北太平 洋 $^{[6]}$. 由于东亚夏季风在 7 月下旬推进到东北地区, 南风气流带来大量的水汽, 导致东北夏季雨带的建 立. 而东亚夏季风强弱的年际变化决定着南风气流 是否能推进到东北地区以及推进的早晚, 进而影响 到东北地区夏季降水的多少和东北旱涝的发生 ${ }^{[7]}$.

除了东亚夏季风的影响以外, 东北夏季降水还 受到中高纬度环流的影响. 何金海等 ${ }^{[8]}$ 指出当前期 2 月北极环状模偏弱, 东北冷浴活动偏强, 东北夏季降 水偏多; 反之, 前期 2 月北极环状模偏强, 东北冷浴 活动偏弱, 东北夏季降水偏少. 武炳义等 ${ }^{[9]}$ 进一步指 出夏季北极极浴中心在北极东、西部之间的转换(北 极偶极子)也与东北夏季降水有关. 当北极极浴中心 位于北极的西部, 中国东北夏季降水增多. 此外, 还 有研究指出东北夏季降水可能和青藏高原冬春季节 的积雪有关 ${ }^{[10]}$.

以上研究主要针对东北夏季降水的建立和撤退 的季节演变过程; 在年际变化的时间尺度上则主要 关注东北夏季平均降水的变化特征. 由于东北夏季 降水存在明显的次季节变化特征, 其汛期降水主要 出现在盛夏的 7 和 8 月. 盛夏汗期降水的年际变化和 初夏 5 和 6 月降水的年际变化特征是否一致? 影响其 年际变化的主要大尺度环流特征又是什么? 本文针 对以上提出的两个问题进行了分析. 分析东北地区 各月降水对应的大尺度环流系统, 有助于了解不同 纬度环流系统对我国东北地区夏季降水年际变化的 影响。

\section{1 数据来源}

本文所用的资料来自于中国气象局国家气候中 心收集整理的中国 753 站的台站观测月平均降水资 料. 我们从中选取了中国东北地区, 包括黑龙江省、 吉林省、辽宁省和内蒙古自治区东部四盟的 79 个测 站(图 1). 使用数据的时间长度为 $45 \mathrm{a}$, 从 1961 到 2005 年. 本文采用的大气环流场资料来自 ECMWF 提供的月平均再分析数据 ${ }^{[11]}$, 使用的变量包括纬向

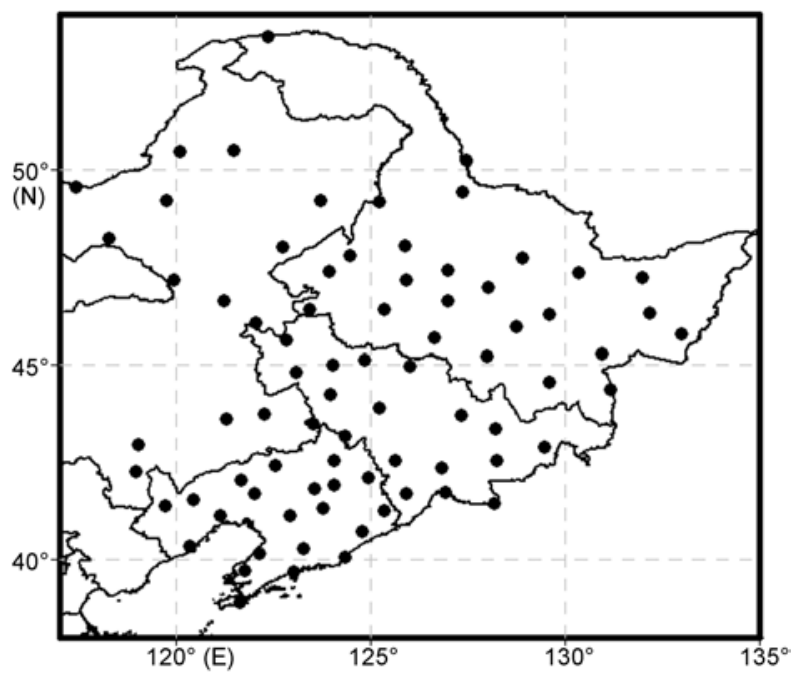

图 1 选取的中国东北 79 个站点分布

风、经向风、气压垂直速度和位势高度. 此外, 为了 计算水汽输送, 本文还采用了来自 ECMWF 提供的 每日 4 次的纬向风、经向风、比湿以及地表面气压再 分析数据 ${ }^{[11]}$. 其水汽输送及其散度的计算方案与陈 际龙和黄荣辉 ${ }^{[12]}$ 一致, 从地表垂直积分到 $100 \mathrm{hPa}$. 由于受到资料长度的限制, 我们选取的时间段为 1961 2002 年. 类似地, 我们也采用 NCEP/NCAR 的 再分析资料做了同样的分析，两种再分析资料的结 果基本一致. 在本文中, 我们只给出了基于 ECMWF 再分析资料分析的结果.

\section{2 东北夏季降水气候特征分析}

利用国家气候中心 1961 2005 年东北地区分布 较均匀的 79 个测站的月降水量资料, 我们分析了东 北地区降水量的时、空分布特征. 1961 2005 年共 $45 \mathrm{a}$ 的区域年平均总降水量为 $552 \mathrm{~mm}$, 其中降水主要集 中在夏季, 春、秋季次之, 而冬季降水最少. 逐月降 水量曲线显示: 东北地区夏季 7 月降水量最多, 可达 $154 \mathrm{~mm} ; 8$ 月降水稍弱, 为 $126 \mathrm{~mm}$. 其中对东北地区 春、夏季农作物的生长等具有重要作用的 5 8 月降水 量占全年降水量的约 3/4. 因此, 5 8 月降水量的多 少、降水空间分布特征对农业生产安全具有显著的影 响. 本文将着重对东北地区 5 8 月降水量特征及影响 其的大尺度环流特征进行分析.

图 2给出了东北夏季 5 8月逐月的降水空间分布. 
东北夏季降水整体表现为由东南向西北逐步减少的 分布特征, 东南部降水约为西北部的两倍. 这种降水 分布特征主要和东北地区的地形分布有关. 受到东 北地区东侧的东北-西南向长白山脉的影响, 南面的 气流受地形影响抬升, 水汽凝结导致降水出现在东 南面的迎风坡, 因此东北地区东南部出现强的降水 中心. 除此以外, 在 6 月和 7 月, 从欧亚大陆上游来 的西风气流受东北地区西北部东北-西南向大兴安岭 山脉的影响, 降水主要出现在西部的迎风坡, 而东部 出现降水极小值(图 2(b)和(c)).

此外，从5 8月的气候空间分布图上可以更加清 楚地看到: 与 5 和 6 月(初夏)相比, 7 和 8 月(盛夏)东 北地区的降水显著加强. 5 月份东北地区降水量在 20 80 mm 之间; 6 月降水量略有增加, 月降水量在 60 110 mm 之间. 7 月降水量可达 100 300 mm 左右,
约为初夏月平均降水的两倍; 8 月, 全区降水量与 7 月相当.

\section{3 东北夏季降水年际变化}

除了存在强的季节变化特征以外, 东北夏季各 月降水还存在明显的年际变化. 图 3 给出了东北地区 79 站平均的夏季 5 8 月逐月降水量的时间序列. 我 们以 5 月为例(图 3(a)). 在 1961 2005 共 45 年中, 5 月的最大降水出现在 2005 年, 月总降水量为 $80 \mathrm{~mm}$ 左右, 超过该月气候平均的一倍; 而在降水量最少的 2003 年, 月总降水量仅仅为 $20 \mathrm{~mm}$, 约为气候平均的 一半. 类似地, 在 6 8 月, 东北降水也表现出强的年 际差异. 东北夏季区域平均 5 8 月逐月的年际变化标 准偏差依次为 $14,21,34$ 和 $40 \mathrm{~mm}$. 值得注意的是,
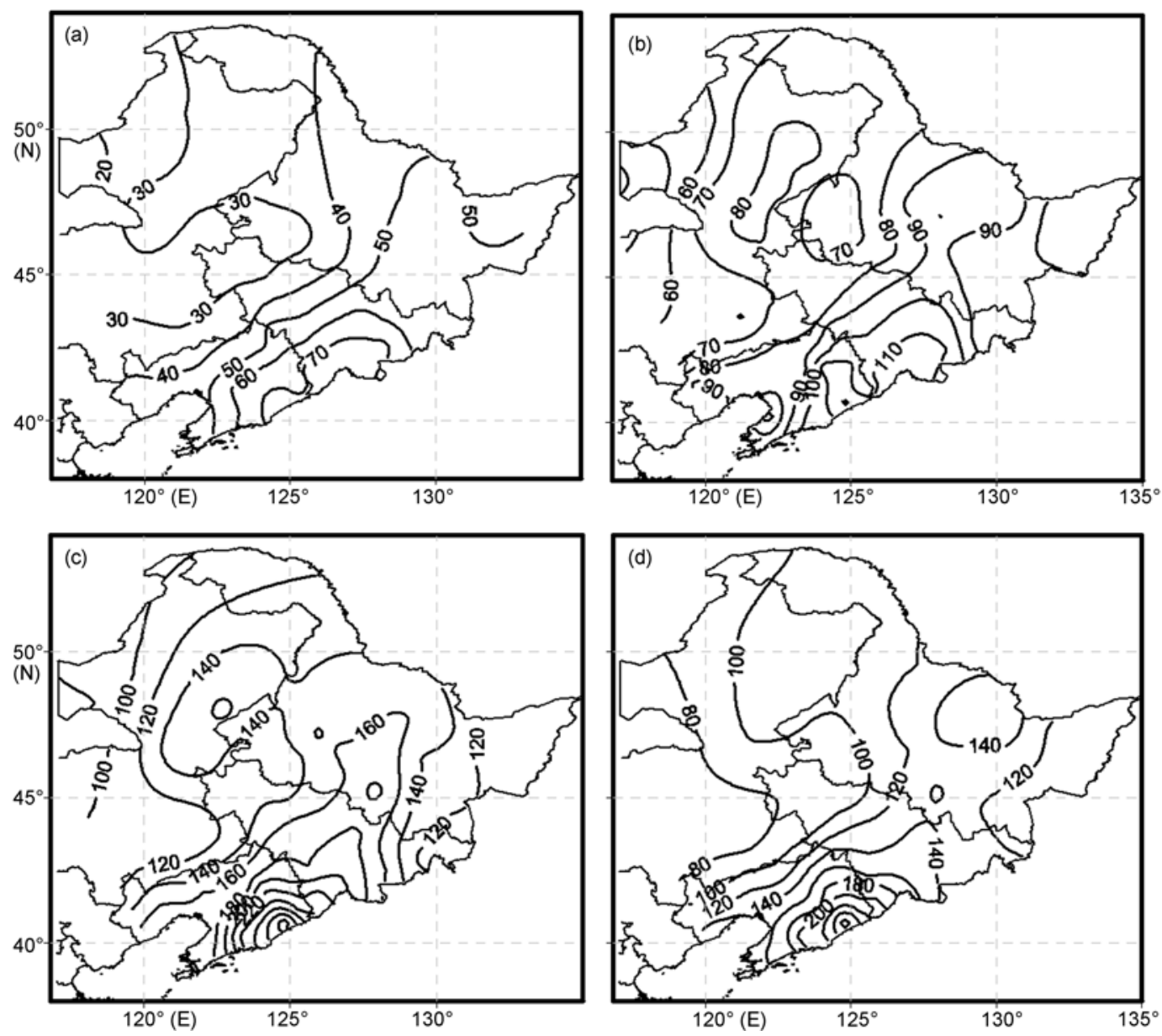

图 2 中国东北月总降水量气候态空间分布

单位为 $\mathrm{mm}$. (a) 5 月; (b) 6 月; (c) 7 月; (d) 8 月 

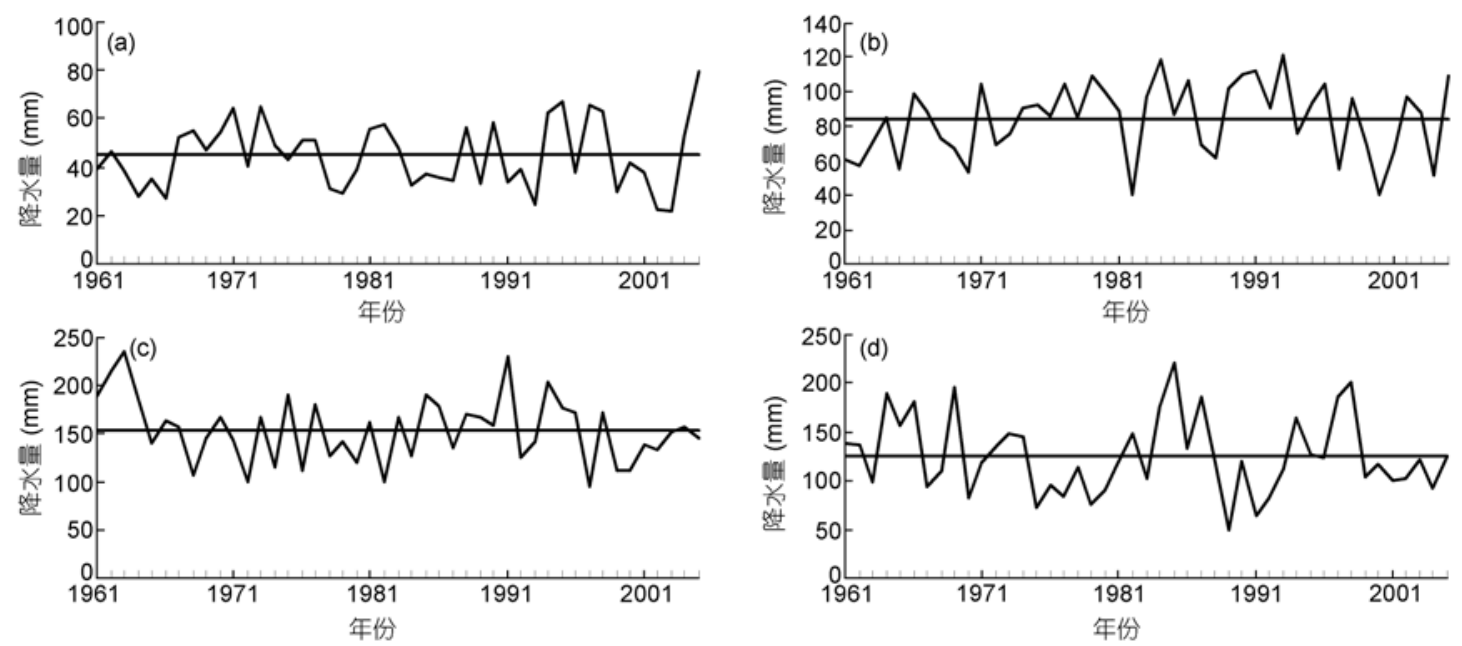

图 3 中国东北 79 站平均月总降水量时间序列(1961 2005)

(a) 5 月; (b) 6 月; (c) 7 月; (d) 8 月

在这 45 年中, 夏季 5 8 月各月的降水并不存在明显 的线性上升或者下降趋势.

79 站区域平均的降水能否代表整个区域的一致 性变化呢? 图 4给出了东北地区 5 8 月区域平均月平 均降水量与东北地区 79 个测站降水同期相关分布. 整体而言, 夏季 5 8 月的区域平均降水指数与全区 79 站降水均表现为正相关. 也就是说, 区域平均的 降水能够较好地代表整个东北地区一致性的年际变 化特征.

除了整个区域一致性的正相关特征以外，相关 系数的空间分布在初夏(图 4(a)和(b)) 和盛夏(图 4(c) 和(d))存在一定差异. 5 和 6 月的同期相关均表现为全 区一致的显著正相关(图 4(a)和(b)), 且相关系数的极 大值主要出现在东北地区的中西部, 大于 0.6. 此外, 5 月份在黑龙江的东南部以及吉林和辽宁的东南部同 时出现另外两个极大值中心. 与 5 和 6 月相比, 7 和 8 月的显著正相关区域主要位于东北地区的东南部; 相关系数的最大值大于 0.7 , 出现在东北地区的东南 部. 并且, 从 7 月到 8 月, 相关系数大值中心逐步从 辽宁向北延伸到吉林和黑龙江省, 这可能和东亚夏 季风从 7 月到 8 月逐步向北的推进过程有关. 以上分 析结果暗示, 影响 5 和 6 月东北夏季降水异常变化的 大气环流特征可能和影响 7 和 8 月东北夏季降水异常 变化的大气环流特征存在差异. 因此, 在下面部分我 们将分别讨论夏季各月东北地区降水对应的对流层 高、低层大尺度环流异常.

\section{4 影响东北地区降水异常的大气环流特征 分析}

\section{1 中低层环流异常}

在 $500 \mathrm{hPa}$ 等压面上(图 5), 东北地区初夏降水偏 多与局地异常低气压显著相关(图 5(a)和(b)). 受到该 异常低气压的影响，东北地区低层主要由西南异常 气流控制(图 6(a)和(b)). 整层的异常水汽输送, 主要 来自于环东北地区的黄、渤海和日本海, 并在东北地 区辐合，对应东北降水增多(图 7(a)和(b)). 而在副热 带地区，此时西太平洋副热带高压主体位于海洋上 空, 其西伸脊线位于 $15^{\circ} \sim 25^{\circ} \mathrm{N}$ 之间(图 5(b)), 主要影 响到我国南方地区，未能影响到东北地区降水.

盛夏, 东北夏季降水的增多则主要和出现在日 本上空的异常高气压有关(图 5(c)和(d)). 与初夏相比, 盛夏西太平洋副热带高压(西太副高)中心逐步北移, 在 8 月其西伸脊线北抬至 $30^{\circ} \mathrm{N}$. 日本上空异常高气 压正好出现在西太副高的西北部，对应西太副高的 西伸北进. 受副高西伸北进的影响, 异常的水汽沿着 西太副高西侧的南风异常(图 6(c)和(d)) 向北输送到东 北地区(图 7(c)和(d)). 值得注意的是: 7 月西太副高西 侧显著的南风异常(图 6(c)) 向北输送水汽仅仅到达东 北地区的东南部, 对应水汽的辐合中心出现在东北 地区的东南部(图 7(c)); 而在 8 月, 南风异常进一步 向北推进到吉林和黑龙江省(图 6(d)), 相应地, 东北 地区水汽输送和辐合中心也向北推进(图 7(d)). 这和 

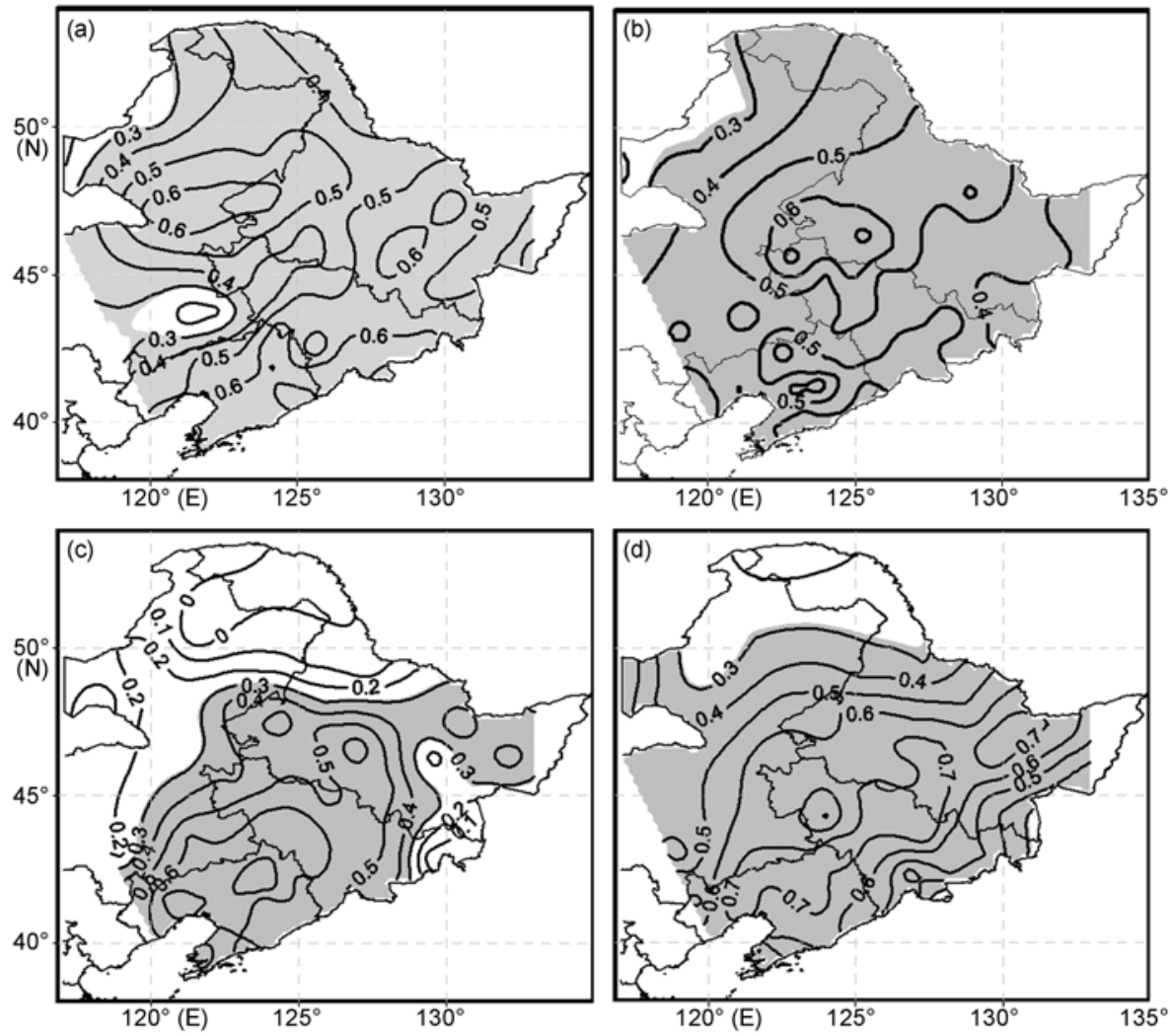

图 4 中国东北 79 站平均月总降水量与该月各个站点总降水量相关系数分布 其中阴影代表相关信度达到 95\%. (a) 5 月; (b) 6 月; (c) 7 月; (d) 8 月
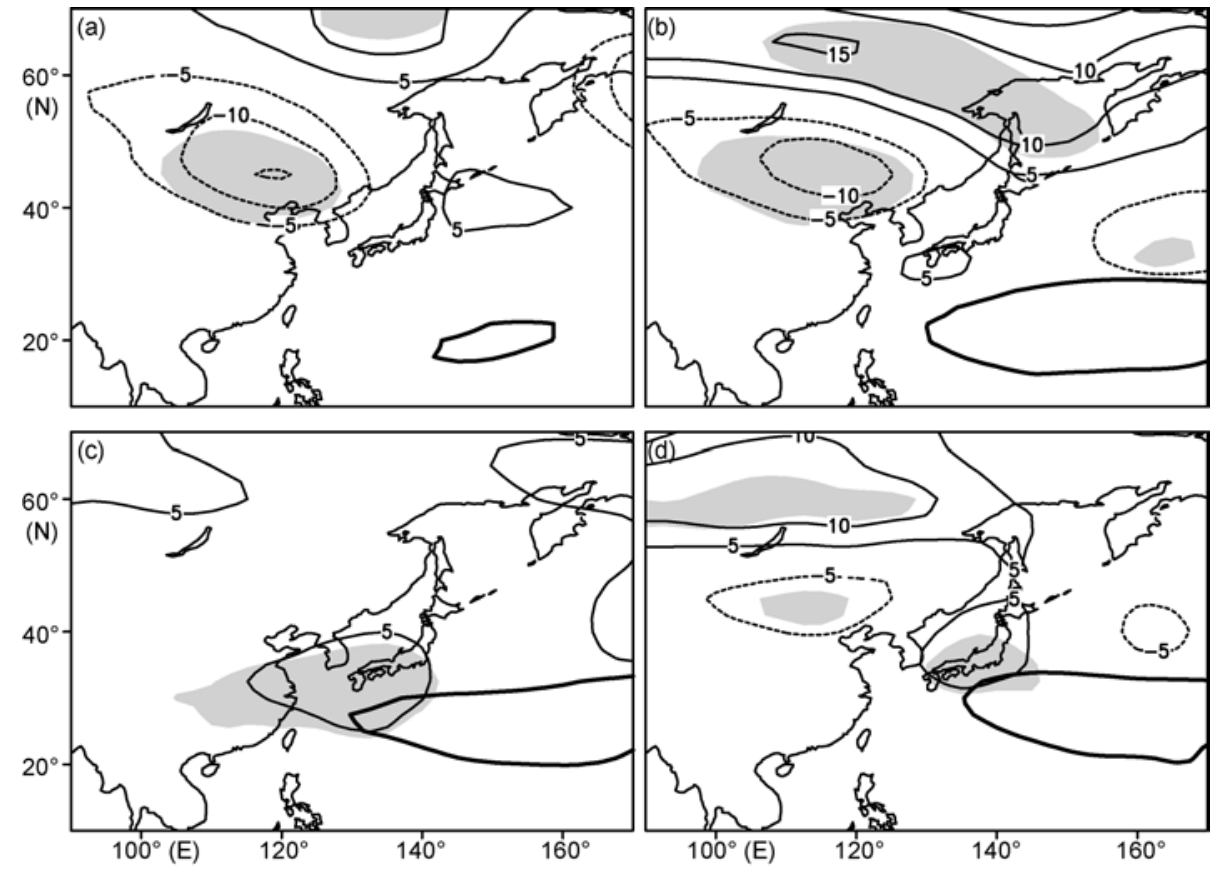

图 5 中国东北 79 站区域平均月总降水量标准化时间序列回归的该月 500-hPa 位势高度场异常分布 阴影代表 95\%信度; 粗实线为气候态 500-hPa 位势高度 5880 位势米线; 单位为位势米. (a) 5 月; (b) 6 月; (c) 7 月; (d) 8 月 

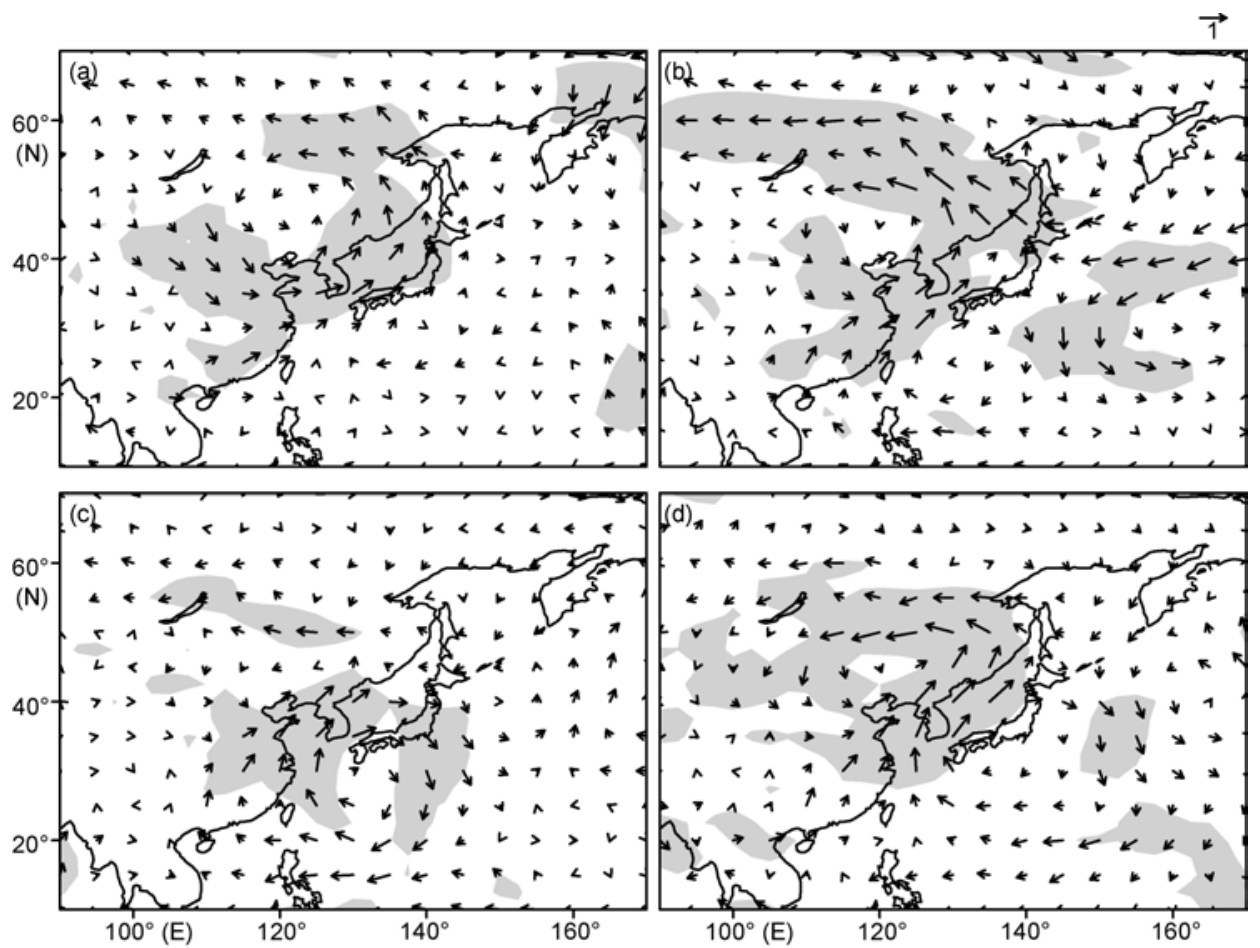

图 6 中国东北 79 站区域平均月总降水量标准化时间序列回归的该月 850-hPa 异常水平风场分布 阴影代表 $95 \%$ 信度; 标尺见图右上方, 单位为 $\mathrm{m} / \mathrm{s}$. (a) 5 月; (b) 6 月; (c) 7 月; (d) 8 月
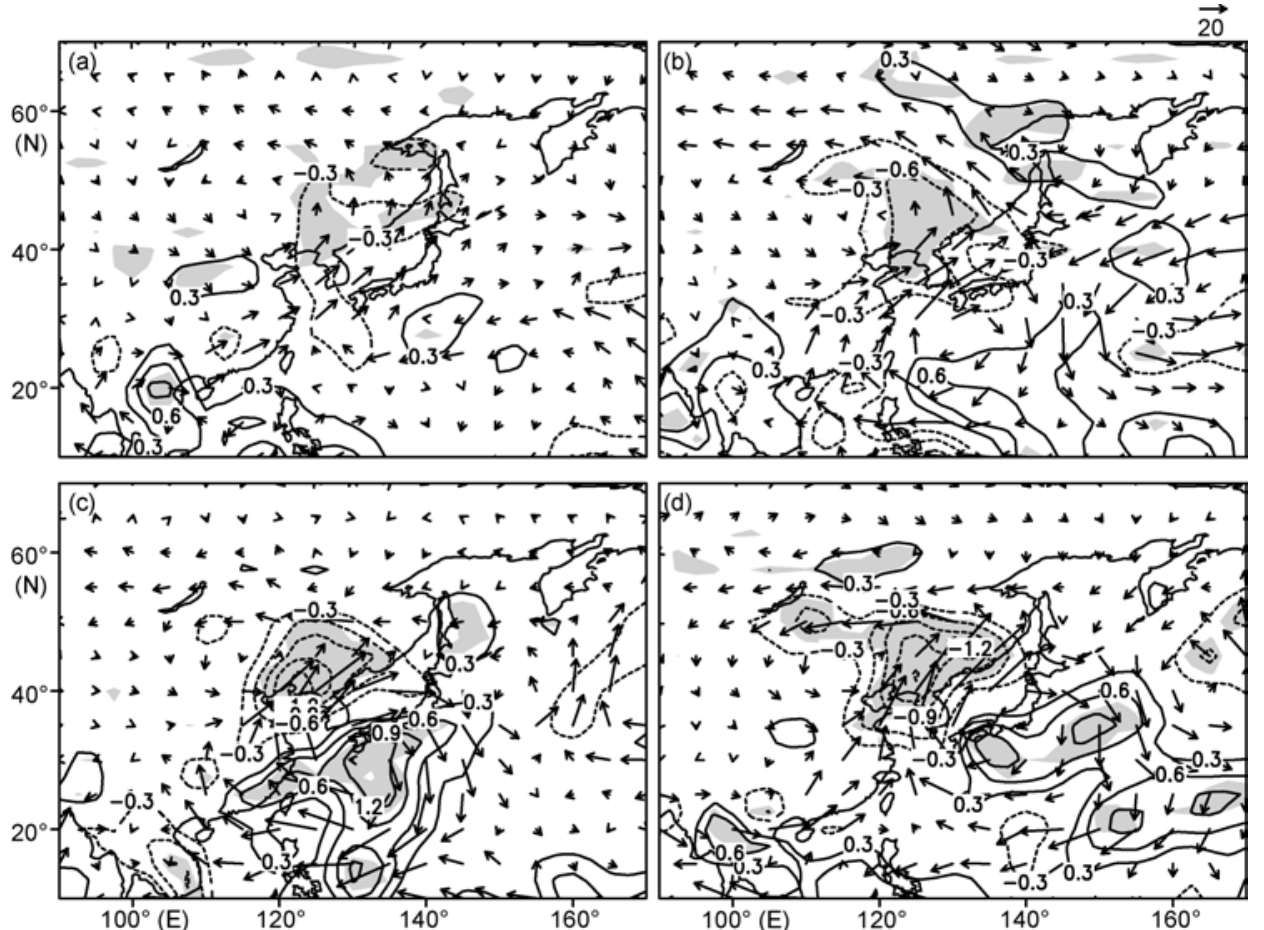

图 7 中国东北 79 站区域平均月总降水量标准化时间序列回归的该月整层水汽输送及其散度

水汽输运是矢量, 标尺见图右上方, 单位为 $\mathrm{kg} /(\mathrm{m} \cdot \mathrm{s})$; 散度是线条, 单位为 $\mathrm{mm} / \mathrm{d}$. 其中阴影代表回归的散度达到 $95 \%$ 信度. (a) 5 月; (b) 6 月; (c) 7 月; (d) 8 月 
相关分析中发现的与东北区域月平均降水相关的降 水异常中心从 7 月到 8 月的向北移动一致(图 4(c)和 (d)), 可能和东亚夏季风逐步向北推进过程有关. 同 时, 在东北地区, 尤其是 8 月, 同样也出现了异常的 低气压中心(图 5(d)), 这和对流层高层上游沿着亚洲 西风急流传播的波活动有关. 我们将在后面的章节 中对这一点作进一步的讨论. 此外, 值得注意的是, 与 7 月份相比, 8 月东北降水还与贝加尔湖以北地区 高压异常有关, 这可能主要来自中高纬度东北亚阻 塞高压的影响.

考虑到东北地处中纬度, 其降水年际变化对应 的环流异常可能存在非线性变化特征, 因此, 我们进 一步对环流场进行合成分析. 首先, 基于东北夏季逐 月的降水时间序列(图 3), 我们分别对其进行标准化, 挑选出大于 1 个标准偏差(东北夏季降水偏多)和小于 -1 个标准偏差(东北夏季降水偏少)的年份. 对应 5 8 月, 挑选出的东北降水偏多年数分别为 $7,7,7$ 和 $8 \mathrm{a}$, 降水偏少的年数为 $7,8,8$ 和 $7 \mathrm{a}$. 然后, 基于挑选出的 降水偏多年和偏少年分别对环流场进行合成分析. 图 8 分别给出了东北夏季逐月降水偏多年(左栏)和偏 少年(右栏)对应的 $500 \mathrm{hPa}$ 位势高度异常的空间分布. 初夏, 对应东北降水增多, 东北局地受到异常低气压 的控制(图 8(a)和(b)); 与之相反, 对应东北降水偏少, 东北局地则受到强的高压异常控制(图 8(e)和(f)), 两 者呈现近似的线性反对称特征. 盛夏, 伴随西太平洋 副热带高压北移, 当其西北部出现异常的高气压, 对 应西太平洋副热带高压西伸北进, 东北降水增多; 而 当其西北部出现异常的低气压, 东北降水减少. 此外, 对应东北夏季降水增多, 东北局地上空为异常低气 压; 而在降水偏少的年份, 局地上空为异常高气压. 值得注意的是, 8 月由于西太平洋副热带高压有所东 撤, 东北降水加强主要由“东北亚阻高-其南侧切断性 斜槽-Bonin 高压” 型环流所控制. 这说明与 7 月份相 比, 8 月东北降水除了受到夏季风推进的影响以外, 还受到中高纬度东北亚阻塞高压的影响. 这可能也 是 8 月份合成结果中异常并不显著的原因. 对降水偏 多和偏少年对应的环流异常相减的合成结果与前面 回归分析的结果(图 5)一致; 初夏显著的异常主要表 现为在东北局地的异常低气压, 而盛夏显著的异常 主要表现为西太平洋副热带高压西北侧的正异常(图 略). 类似地, 对 $850 \mathrm{hPa}$ 的风场以及整层水汽的输送 及其散度进行合成分析, 其结果均呈现近似线性反
对称的空间分布特征, 并且降水偏多年和偏少年的 显著差异均与回归分析结果一致(图略).

\section{2 高层环流异常}

在对流层上层 $(200 \mathrm{hPa})$, 对应初夏东北降水增 加, 其西北部贝加尔湖地区存在显著的气旋式异常 (图 9(a)和(b)). 这种气旋性环流异常应该和初夏东北 冷浴的频繁发生有关. 与对流层低层相比(图 6(a)和 (b)), 该异常的气旋性环流随着高度向西倾斜. 在对 流层上层, 气旋式异常的中心位于贝加尔湖附近, 而 在对流层低层, 气旋式异常出现在贝加尔湖以东. 这 种向西的倾斜代表了中纬度的斜压不稳定事件 ${ }^{[13]}$, 上升气流容易出现在异常低压之前的东北地区. $\mathrm{Hu}$ 等 ${ }^{[14]}$ 对东北冷浴进行了统计分析, 他们的结果表明 夏季东北冷浴主要在贝加尔湖及偏东地区形成, 这 与图 9(a)和(b)中对流层高层异常的气旋性环流位置 接近. 在该地区, 东亚高空西风急流轴北侧强的气旋 性环流切变将有利于东北冷浴形成. 进一步, 基于 $\mathrm{Hu}$ 等 ${ }^{[14]}$ 统计的月东北冷浴持续时间, 我们计算了初 夏 (5 月和 6 月)总的冷浴持续日数与同期东北夏季降 水的相关系数; 该相关系数在 1961 2002 年共 42 年 期间为 0.43, 达到 99\%的显著性水平检验(图 10(a)). 综合以上分析, 初夏东北地区降水年际变化主要和 东北冷涡活动有关.

然而, 另一方面, $\mathrm{Hu}$ 等 ${ }^{[14]}$ 对东北冷浴的统计结 果还表明, 夏季(6 8 月)降水中冷浴有关联的降水量 只占总降水量的 $30 \%$ 不到. 我们认为这可能和初夏 降水量比较小、盛夏降水主要受东亚季风影响有关. 对应东北盛夏降水增强, 局地上空东亚对流层高层 出现反气旋性环流异常, 该反气旋异常对应着东亚 高空急流轴南侧的东风异常和急流轴北侧的西风异 常, 即东亚高空西风急流偏北(图 9(c)和(d)). Lin 和 $\mathrm{Lu}^{[15]}$ 的结果说明, 当东亚高空西风急流轴偏北时, 低层西太副高相应地也偏北, 这和本文的结果一致。 7 月降水对应的环流异常中已经看不到初夏降水对应 的中心位于贝加尔湖的气旋式异常, 说明此时冷浴 对降水异常的影响不大. 8 月, 尽管有一个气旋式异 常，但是这个气旋式异常位置明显比初夏时的偏南， 其中心位于东亚高空急流轴上(大约为 $40^{\circ} \mathrm{N}$ 左右), 远低于东北冷浴频发中心. 东北冷涡频发中心大约 位于 $50^{\circ} \mathrm{N}$ 左右 $\left(\mathrm{Hu}\right.$ 等 ${ }^{[14]}$ 文章中图 5(b)), 正好和初夏 气旋式异常出现的位置吻合. 类似地, 我们计算了盛 

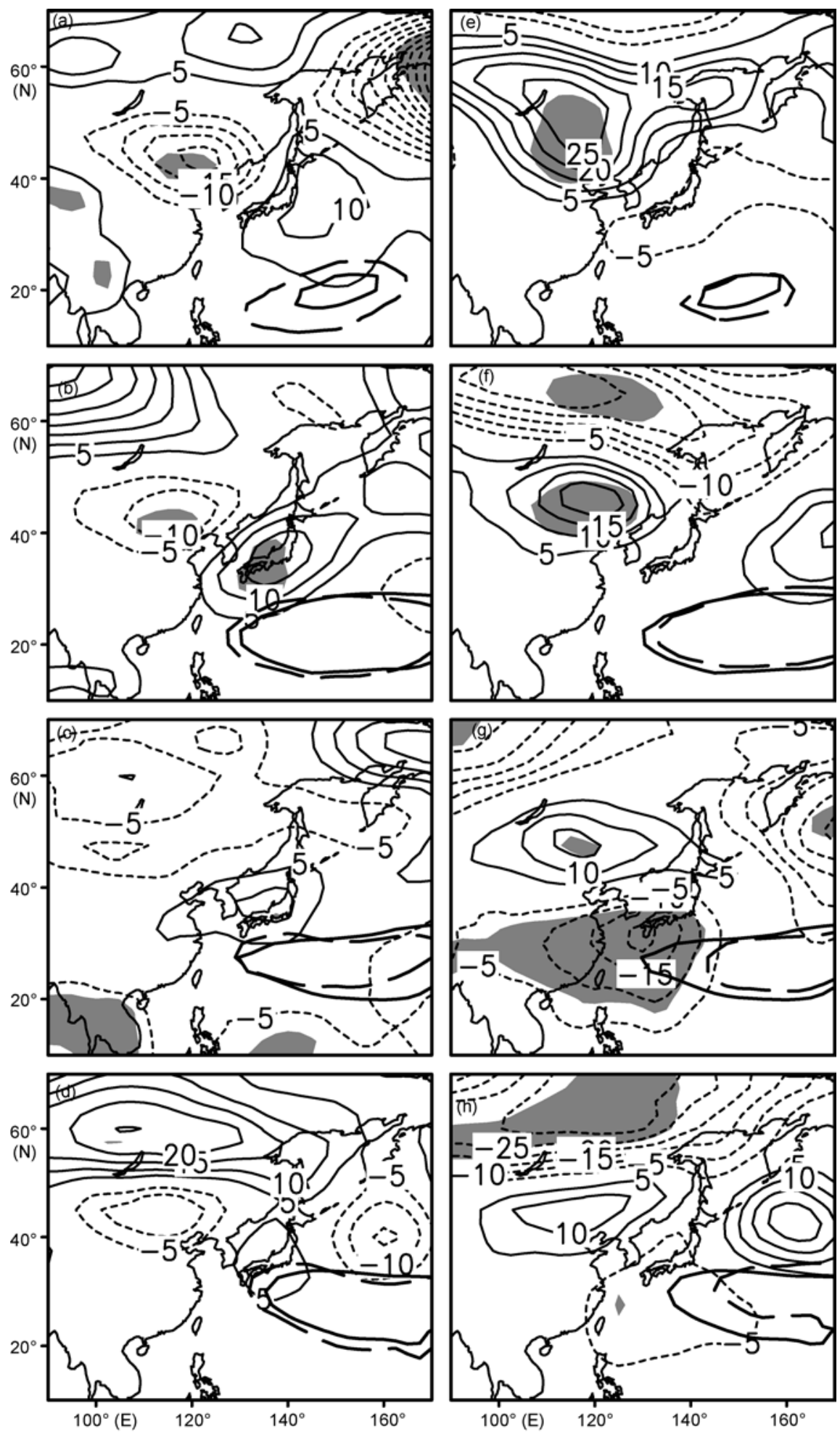

图 8 基于中国东北 79 站区域平均月总降水量标准化时间序列合成的该月 500-hPa 位势高度场异常分布 左栏对应东北降水偏多年，而右栏对应东北降水偏少年. 阴影代表 $90 \%$ 信度; 粗实线为气候态 $500-\mathrm{hPa}$ 位势高度 5880 位势米线, 而粗虚线为 异常年的 500-hPa 位势高度 5880 位势米线; 单位为位势米. (a) (e) 5 月; (b) (f) 6 月; (c) (g) 7 月; (d) (h) 8 月 

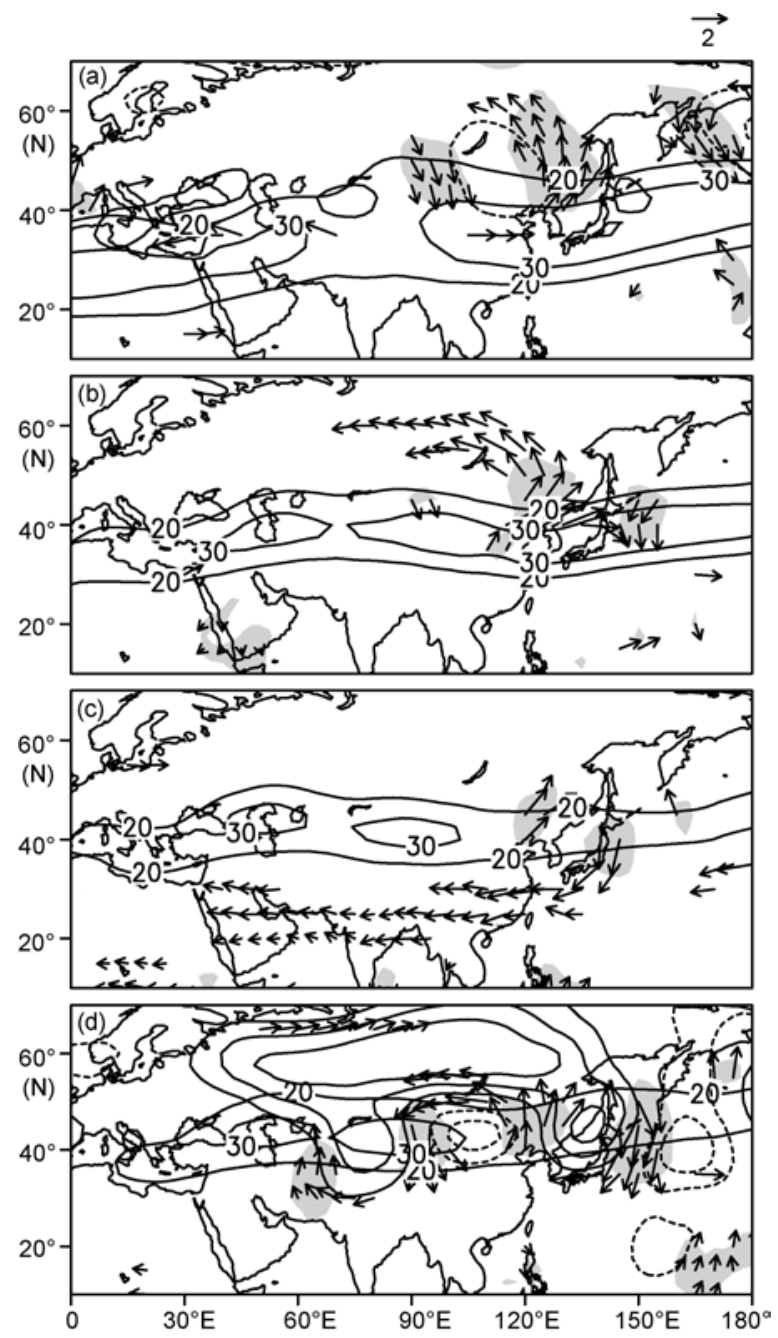

图 9 中国东北 79 站区域平均月总降水量标准化时间序列 回归的该月 200-hPa 异常水平矢量风场分布以及位势高度 异常 $(\mathbf{d})$, 线条)

矢量为 $95 \%$ 信度对应的水平风场, 单位为 $\mathrm{m} / \mathrm{s}$, 标尺见图右上方; 阴 影代表经向风分量达到 95\%信度. 实线表征纬向风速大于 $20 \mathrm{~m} / \mathrm{s}$ 的 西风急流所在位置. 图(d)中线条间隔为 5 位势米, 其中 0 等值线省 略. (a) 5 月; (b) 6 月; (c) 7 月; (d) 8 月

夏(7月和 8 月)总的冷涡持续日数与同期东北夏季降 水的相关系数; 其相关系数在 1961 2002 年期间仅为 0.14(图 10(b)). 这说明在盛夏, 东北冷浴活动对局地 夏季降水的影响并不显著. 下面我们将会谈到, 8 月 的气旋式异常实际上和沿着欧亚大陆高空急流东传 的波列有关.

从图 9(c)和(d)中, 我们可以看到盛夏东亚反气 旋式异常似乎还和欧亚大陆上空的环流异常相关联. 7 月, 东亚反气旋式异常和亚洲西风急流南侧的东风
异常连在一起, 该东风异常从我国华南上空穿过印 度半岛, 一直向西伸到阿拉伯半岛. 目前还不清楚这 个东风异常产生的原因. 8 月, 我们可以看到东亚反 气旋异常和贝加尔湖以南的气旋式异常及其以西的 另一个反气旋异常，一起构成纬向上的一个波列.

以往的许多研究结果 ${ }^{[16 ~ 21]}$ 都说明沿着亚洲高空 急流存在着自西向东传播的波列. $\mathrm{Lu}$ 等 ${ }^{[16]}$ 发现沿着 北非到东亚的西风急流存在一个明显的遥相关型, 提出通过沿西风急流遥相关型, 东亚夏季风可以受 到印度季风、甚至大西洋地区热源异常的影响. Enomoto 等 ${ }^{[17]}$ 将这种波列称为 “丝绸之路(Silk Road)” 遥相关型, 因为夏季欧亚高空西风急流所处的纬度 大致为 $40^{\circ} \mathrm{N}$, 恰巧为丝绸之路所在的纬度. 布和朝 鲁等 ${ }^{[22]}$ 分析了梅雨期 EAP 事件的演变特征, 指出在 欧亚大陆中高纬及亚洲急流区向下游频散的 Rossby 波和东亚沿岸经向频散的波列相互作用、相互锁定. 图 9(d) 表明 8 月东北降水异常与沿着亚洲高空急流自 西向东传播的波列有关，该波列从 $60^{\circ} \mathrm{E}$ 沿着亚洲西 风急流向东传播到日本以东洋面. 从这里可以看到, 8 月贝加尔湖以南的气旋式异常确实与沿着高空急流 东传的波列有关.

综合上述分析结果，我们认为东北地区初夏降 水异常主要和东北冷涡活动有关; 而在盛夏, 伴随着 东亚夏季风环流的北进, 东北地区降水偏多则主要 和局地对流层高层东亚高空西风急流位置异常北移 以及对流层低层西太副高的西伸北进有关, 并且受 到东亚上游亚洲大陆上空中低纬度环流异常的影响.

\section{5 小结和讨论}

利用中国东北地区 79 个台站观测的月平均降水 资料和 ECMWF 再分析资料, 我们分析了东北地区 降水年际变化的主要特征, 指出其年际变化具有显 著的次季节尺度特征：初夏东北降水与整个区域均 为显著性的正相关, 其相关的中心出现在东北地区 的中西部; 而在盛夏, 显著的正相关出现在东北地区 的东南部. 进一步我们讨论了与东北地区逐月降水 变化相关的对流层高、低层大气环流特征, 发现其对 应的环流特征在初夏和盛夏也存在显著的差异.

初夏, 东北地区降水异常主要和东北冷涡活动 有关. 对应东北冷涡活动频繁，东北地区西北侧对流 层出现随着高度向西倾斜的气旋性环流异常. 在该 

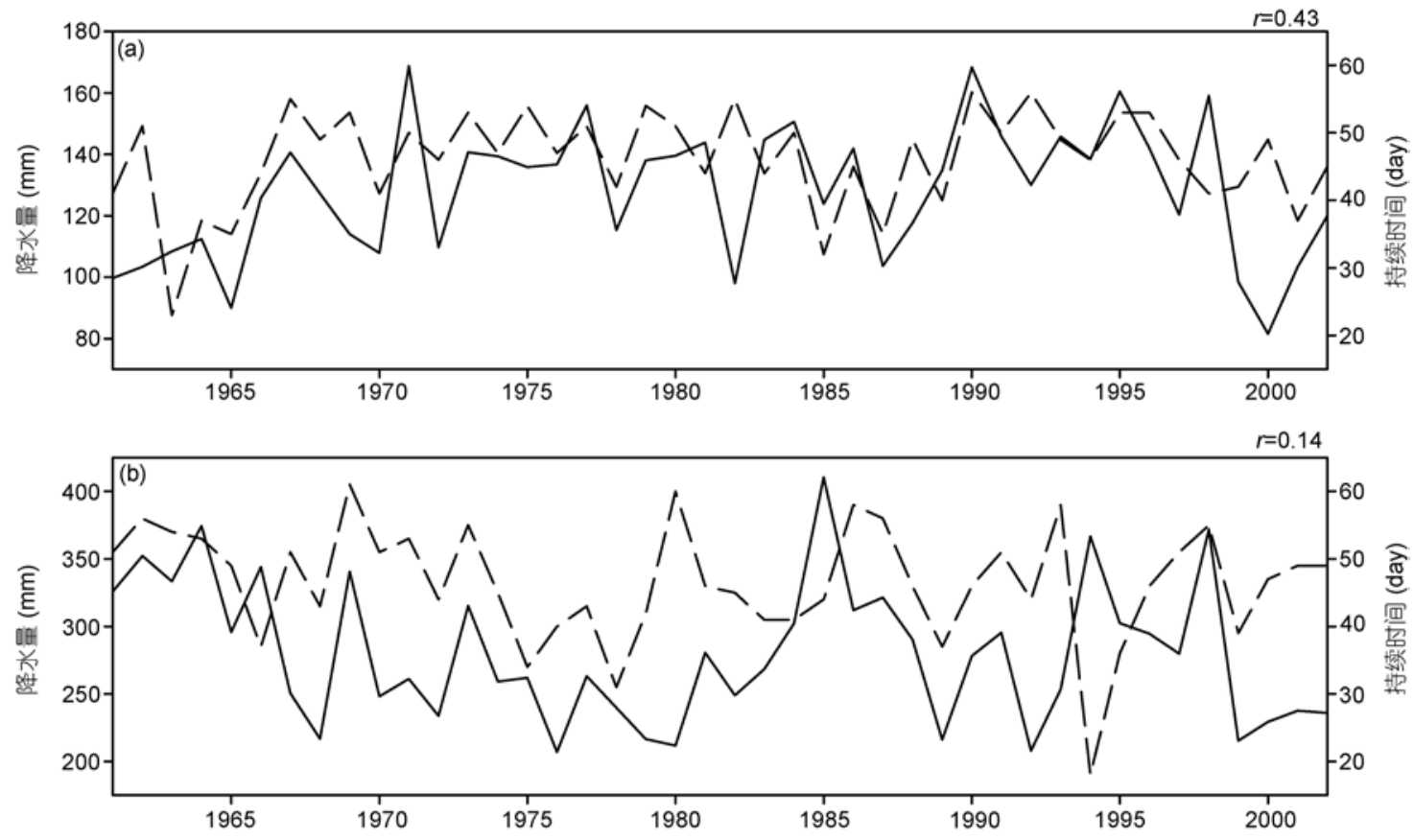

图 10 东北初夏 $(a)$ 和盛夏 $(b)$ 降水总量(实线)和东北冷涡持续日数(虚线)的年际变化时间序列(1961 2002)

降水总量的单位为 $\mathrm{mm}$ (左标尺), 冷涡持续日数的单位为 $\mathrm{d}$ (右标尺). 两者的相关系数在初夏和盛夏分别为 0.43 和 0.14

向西倾斜的异常气旋性低压环流影响下，其东侧强 的斜压不稳定性有利于在东北地区形成异常上升气 流，东北地区初夏降水偏多.

盛夏，东北地区的降水偏多主要受到局地对流 层高层东亚高空西风急流北移、以及对流层低层西太 平洋副热带高压西伸北进的影响. 对应西太平洋副 热带高压的西伸北进, 其西北侧增强的西南风气流 有利于更多的水汽由低纬度西北太平洋地区向东北 地区输送, 使得东北地区盛夏降水显著加强. 与 7 月
份相比, 8 月西太平洋副热带高压变化的影响有所减 弱; 东北降水除了受到夏季风推进的影响以外, 还受 到中高纬度东北亚阻塞高压的影响.

值得注意的是，盛夏东北夏季降水还与 7 月急流 轴南侧从我国华南上空穿过印度半岛一直到阿拉伯半 岛的东风异常, 以及 8 月从 $60^{\circ} \mathrm{E}$ 沿着亚洲西风急流向 东传播的波活动有关. 这些结果说明盛夏东北地区的 降水可能和上游亚洲大陆上空中低纬度环流异常变化 有关, 但具体的联系机理还需要进一步的研究.

\section{参考文献}

1 郭其蕴, 王继琴. 近三十年我国夏季风盛行期降水的分析. 地理学报, 1981, 36: 187-195

2 Ding Y H. Summer monsoon rainfalls in China. J Meteor Soc Jp, 1992, 70: 373-396

3 丁一汇, 李崇银, 何金海, 等. 南海季风试验与东亚夏季风. 气象学报, 2004, 62: 561-586

4 廉毅, 沈柏竹, 高枞亭, 等. 东亚夏季风在中国东北区建立的标准、日期及其主要特征分析. 气象学报, 2003, 61: 548-558

5 孙力, 安刚, 丁立, 等. 中国东北地区夏季降水异常的气候分析. 气象学报, 2000, 58: 16-19

6 Sun L, Shen B Z, Gao Z T, et al. The impacts of moisture transport of East Asian monsoon on summer precipitation in Northeast China. Adv Atmos Sci, 2007, 24: 606-618

7 孙力, 安刚, 唐晓玲. 东北亚地区夏季 $850 \mathrm{hPa}$ 南风异常与东北早涝的关系. 大气科学, 2003, 27: 425-434

8 何金海, 吴志伟, 祁莉, 等. 北半球环状模和东北冷浴与我国东北夏季降水关系分析. 气象与环境学报, 2006, 22: 1-5 
9 武炳义, 张人禾, Rosanne D A. 北极偶极子异常与中国东北夏季降水. 科学通报, 2008, 53: 1422-1428

10 沈柏竹, 廉毅. 青藏高原积雪与东北地区夏季冷浴雨季降水关系的初探. 吉林大学学报(地球科学版), 2004, 34: 112-118

11 Uppala S M, Allberg K, Simmons P W, et al. The ERA-40 re-analysis. Quart J Roy Meteor Soc, 2005, 131: 2961-3012

12 陈际龙，黄荣辉. 亚洲夏季风水汽输送的年际年代际变化与中国陆地旱涝的关系. 地球物理学报, 2008, 51: 352-359

13 Holton J R. An Introduction to Dynamic Meteorology. 3rd ed. California: Academic Press, 1992

14 Hu K X, Lu R Y, Wang D X. Seasonal climatology of cut-off lows and associated precipitation patterns over Northeast China. Meteorol Atmos Phys, 2010, 106: 37-48

15 Lin Z D, Lu R Y. Interannual meridional displacement of the East Asian upper-tropospheric jet stream in summer. Adv Atmos Sci, 2005, 22: 199-211

16 Lu R Y, Oh J H, Kim B J. A teleconnection pattern in upper-level meridional wind over the North Africa and Eurasian continent in summer. Tellus Ser A-Dyn Meteorol Oceanol, 2002, 54: 44-55

17 Enomoto T, Hoskins B J, Matsuda Y. The formation mechanism of the Bonin high in August. Quart J Roy Meteor Soc, 2003, 129: 157-178

18 Enomoto T. Interannual variability of the Bonin high associated with the propagation of Rossby waves along the Asian Jet. J Meteor Soc Jp, 2004, 82: 1019-1034

19 Ding Q H, Wang B. Circumglobal teleconnection in the northern hemisphere summer. J Clim, 2005, 18: 3483-3505

20 廖清海, 陶诗言, 王会军. 东亚地区夏季 7 8 月大气环流季节演变异常的内部动力学过程. 地球物理学报, 2006, 49: 28-36

21 杨莲梅, 张庆云. 夏季亚洲副热带西风急流气候特征. 气候与环境研究, 2008, 13: 10-20

22 布和朝鲁, 施宁, 纪立人, 等. 梅雨期 EAP 事件的中期演变特征与中高纬 Rossby 波活动. 科学通报, 2008, 53: 111-121 